\title{
The cultural influence on consumer behavior in India
}

\author{
Ram Shrivastava and Manish Nagaich $\bowtie$
}

Received:28.12.2012

Revised:25.01.2013

Accepted: 23.03.2013

\begin{abstract}
This paper examines the effect of culture on the Indian retail market and the behavior of native consumers. Here we have tried to study in the change of behavior of consumers and their concern for their culture. Today's era can be quoted as the era of consumerism where the market is designed and customized as per the need of hour. The focus is laid on the emerging trends in shopping and the changing shopping habits of Indians. Today the market has entirely changed the way of celebrating and living of consumers, on the other end Indian customers have accepted these re-design markets which are the resultant of the Globalization and Media, which is the most efficient and effective path of advertisement and awareness
\end{abstract}

\section{Keywords: Cultural, consumer, behaviour, retail}

\section{Introduction}

Consumer behavior is a fast growing application oriented discipline of study. Brisk strides in the area of technology and digital communication are influencing consumer behavior in a significant way, the consumer behavior is dynamic, complex and multidimensional process and reflects the totality of consumer decision with respect to acquisition, consumption and use of disposal activities, there is a perpetual interaction among people's environment, Thinking, feeling and behaviors. We, as consumers. Exhibit very significant difference in our buying behavior and play an important role in local, national, or international economic condition. One of the very few aspect common to all of us is that we are all consumers and the reason for a business firm to come in to being is the presence of consumers, who have unfulfilled or partially fulfilled needs and wants (Robbins Stephen P, 2002). No matter who we are- Urban or rural, male or female, young or old, rich or poor, educated or uneducated, believer or non-believer or whatever we are consumers. We consume or use on a regular basis the things like food, shelter, clothing, vehicle, fuel, education, stationary, entertainment, domestic

\footnotetext{
Author's Address

Agra Public College of Technology and Management, Agra E-mail: manish.nagaich@gmail.com
}

help, health care services, comforts, luxuries, necessities and even ideas etc.Most marketers today understand the significance of marketing concept, which means they are keen to understand their customers and are committed to serving them by developing those quality products and services and selling them at a price that gives consumers high value (Etzel M.J., Walker B.J. and Stanton William J., 2006). Culture is an important aspect in today's consumer era which influences consumers through the norms and values established by the society in which they live. It is the broadest environmental factor that influences consumer behavior. Cultural values are enduring and any attempt to change them generally fails, hence it can be an agreeable fact that in the making of one's own surroundings culture is an important factor which lies in the composition of life styles.

\section{Objective}

The objective of our study is to observe the changes in the behavior of consumers in last twelve years i.e from 2000-2012, which has got a remarkable expression and given an overwhelming response to the market. The market has been customized with the sure shot strategies with most suitable choice of product in the best satisfying manner for the consumers along with their cultural needs. 


\section{Study site}

The study were chosen as the shopping complexes and retail stores which have arrived almost 10 years before in the cities like Agra, Meerut, Bareily, and Delhi NCR. We visited all these cities which are well equipped with prominent retail stores. We visited all those sites personally to interact with the shoppers and the staff and the management of the retail stores like Vishal Mega Mart, Shopper's Stop and Big bazaar which celebrates Wednesday as haftekasabsesasta din (The cheapest day of the week).

\section{Study}

In a premises like India, where the date of civilization goes back to thousands year back. Cultural is the important aspect to study, where the rituals and celebrations are the part and parcel of the masses life. In the era of globalization, the rituals and celebrations have got a unique and specific way to be organized on social platform. This trend has given a different scene to the Indian market, where the buyer is very conscious and has got very expressive to show his/her zeal in a unique way. This paper will examine the impact and influence of culture on the society in terms of their changing life styles, financial status, the urge to maintain their norms of culture and accordingly their buying behavior. This work is the resultant of my personal experience, observations and the gist of the dialogues which $i$ sat up in the different social classes in Northern India. The various levels of middle class are being chosen for the study who are the big portion of cons (meristic society Luthansfred, 2011) Before dipping our self into the topic the concept of culture is need to be explored. D.J. Mc Cart and NareshMalhotra have defined culture as,"the complex hole, that includes knowledge, art, law, morals, customs and any other capabilities and habits acquired by humans and members of society". Any view which is liked and then accepted by the group of people and is practiced within them later or sooner it becomes the foundation of culture. In other words the language, religion, knowledge, laws, art, works and it's patterns, Social customs, festivals, celebrational pattern and foods of a society are the critical factors and parameters to study culture. This cultures influences consumers through the norms and values established by the society. Infact culture includes everything which is exhibited from personality of an individual. The impact of culture is automatic and almost invisible and its influence on behavior is usually taken for granted. If we talk about its characteristics, it's invented, learnt, shared and satisfies needs. Somehow they are similar but different and non-static. Since cultures are not static and change rapidly or slowly in different societies, this becomes quite an important consideration from the marketer point of view that what and how to propose a product or service to the target customers. As it is quiet distinguishable that the role of women in India was confined more within the house hold since a long time. As a norm of society they were made married at an early age, bore children and looked after home making duties. In the last decade a developed seem with the pace of modernization has starting arising from urban reasons where women are becoming more extrovert and ensuring their presense and partnership on the front of every sociological aspect (Mc. Carthy \& Perrlault, 2007).This development has been a gradual process in the last Decade of last Century and has got a faster pace steadily in the last Decade. In the changing of this scenario the role of government policies for the empowerment of women has played a crucial role more women started receiving higher education and one more step ahead they turned for technical and professional education. Women are entering in various professions, which earlier were the domains of men. As a result dual income households are increasing rapidly. Here it is necessary to quote that small family and increased buying power which certainly given several and important opportunities to the marketers. This empowerment of women is 
the first factor on the Cultural Influence on Consumer Behavior.Such cultural changes are directly attributed to the influence of Global culture, mass media and others. By the impact of the same we very often observe that youths hold the issue of marriage till they are employed, well settled and have a satisfactory income levels. This entire scenario has turned up the picks of the market. Articles may not sold in the bulk per unit but the quantity increases in numbers."For instance energy drinks are purchased in a specific quantity with various flavors for the whole month in a family but according to the tastes, age, and gender of each individual", says Mr. anildhawan the distribution manager of Vishal Mega Mart with all zealful smile MrRakeshRanjan of Shoppers Stop nodes on the question that how was the sales of woolen garments went. He replies we had a wonderful sale on the occasion of Christmas Lohri and MakarSankranti. Chock lets have taken the privilege to greet people on occasions instead of other sweets $n$ edible giftsRakesh adds the statements. He says we are observing a high altitude change in the buying behavior of the customers who actually have started valuing their customs (Satish k Batra and S H HKazmi, 2008). DharmeshPathakincharge FMCG outlet of Big Bazaar gives his thoughtful statement very interestingly,"Shikanji(the lemon drink) is been replaced with squashes, colas, and other readymade drinks," and out of way he speaks that Postal amenities like Post cards, Inland, and Postal Envelops have been replaced with S.M.S, M.M.S., and $\mathrm{E}$-mails. Bouquets have taken the place of garlands. More over these all changes show the pattern of current consumer behavior very peculiarly.This shows that the culture is perpetual to move but the slow and slight changes do occur with the pace of time. In compound families the life style and habits of each member used to be almost same, But the last decade seems to be a transition period where the freedom and scope for the own has came in to being and people have got their own way for desired lifestyle. The reason is quite obvious that it is a contemporary cultural influence on consumers habits. The noodles are the part and parcel of the Tiffin's of kids today. This upcoming generation would not be aware of colony's grocery shop. They would not be able to recognize the grains like wheat but shall understand so well to purchase the chocolates, oats and other articles from the retail store chain. This all encompasses the scene in the direction of changes. Handsome amount of earned money has got its way to be spent under the influence of globalization. This is breaking the traditional patterns of purchasing and wants to breathe out under the one roof solutions. This also seems the cultural effect in the habits of consumer. Consumer is ready to pay money on the cost of saving their precious time. Due to all these factors marketers do get an opportunity for the business hence and providing all the best possible solutions to the public and in the form of goods, services and ideas. If forecast gets an approximation, the cultural influence in consumer will be requiring service oriented market where a phone call or click shall get the desired things done within no time. Lets have a glance of few festivals which are celebrated by Indians, Diwali, which is also known as business festival of the nation and AkshayTrutiya the day of collecting assets which are never faded. These both are the festivals which are concerned directly to the Bullion market which deals with the transaction of money and gold.Indian customs refer to the purchase of gold on these festivals as it is said that this purchase of gold brings happiness, prosperity, and joy to the lives. Last five years have witnessed a heavy advertising and aggressive campaign for the celebrations of AkashyaTrutiya. So many schemes by the jewellers are launched and results are unveiled by the next day's newspaper which say the transaction of gold and money in the format of hundreds of crores in a day. It gives a clear cut picture of the influence of culture on the buying behavior of Indian customers or it's a glimpse of influence of festival over the 
business. We have been celebration friendly since centuries (Batra and Kazmi, 2008). Diamond has always levied as a thirst for people. Making it easily affordable with the slogans like "HEERA HAI SADA KE LIYE" has awakened a new urge to the today's civilization. If we glance at a family unit where newly born child creates a need to think for his parents to plan his future in terms of career, studies, marriage and settlement. An utmost amount of money is saved for all the above said issues and is spend in for all the best possible studies, shopping of jewellery, cloths and other dimensions of studies and designer marriages. Here comes a question whetherits worthy or not to spend saved money on the name of culture and culture only?

But undoubtedly the increased and spreaded trend of designer marriages, beautiful and unique celebrations of festivals,admiring life styles of celebrities have given a boom to Indian markets.

This positive creeping of Indian bullion market is the direct effect of culture on Indian customers, who have gone fun and celebration loving, who have become fond of a natural and admiring lifestyles. Who have gone well aware with the traditions and maintain them with the display of unique behavior of purchase. This all has given new wings to shoppers paradise and to the marketers who actually serve the society with the dual motives one to serve society and second is to earn profit for the growth of his enterprise and self.

\section{Results and Discussion}

Indian civilization is as old as the remains of civilization are found in Mohan Jodaro, Greece and Rome. The symbol of culture like the coin which was found in the excavation of Indus valley civilization on which the picture of bull is carved. India is a country where festivals fall everyday and we celebrate them accordingly. This factor of our culture has made us celebration loving and in the last decay the marketers have suggested a unique University and Dr A.K Singh My Colleague for their inspiration and encouragement way for our expression of celebration which we as a customer have accepted it. Today the basic characteristic of Indian consumer seems to take a new shape where he wants to spend his money for the sake of preserving his cultural instincts along with his modern life style. We prefer to eat continental food on the occasion of a traditional festival. Infect it is a remarkable fusion of globalized lifestyle and the preservance of culture. Again it is re-quotable that the masses of India are being served by the International market along with domestic one, which is created for the sake of serving the cultural needs in the best suitable manner.

\section{Conclusion}

The last decade has witnessed a great transitional period of the behavior of consumer. The globalization has made people awared about the global trends. In Indian sub-Continent the effect of globalization is remaining same and seems to merge with cultural prospective, as the culture in this sub-continent is directly linked with the factor of eternity. We see a great impact on the buying behavior of customers who are really concerned with their own rituals and traditions and are merging both to lead their life. This need of these customers is being satisfied by the efficient market of today which are prone to offer lucrative scheme, financial assistance and all solution under one roof.

\section{Acknowledgements}

Authors are highly thankful to Dr. Vikrant Shastri, Director U.I.M.S Agra, for his valuable and moral boosting during the writing of article. We would be failed in our duties if we want express our gratitudes to Mr Anil Dhawan of Vishal Mega Mart, Mr RakeshRanjan of Shoppers Stop and Mr. DharmeshPathak of Big Bazaar.We express our heartfelt gratitude's to $\mathrm{Dr}$ R.B.Singh Agra 
The cultural influence on consumer

\section{References}

Robbins Stephen P 2002. Organizational Behavior (Pearson Education $13^{\text {th }}$ edition)

Etzel M.J., Walker B.J. and Stanton William J. 2006. Marketing Concept and cases special Indian edition (Tata McGraw Hill $13^{\text {th }}$ edition)
Luthansfred 2011. Organisational Behavior (Tata McGraw Hill $10^{\text {th }}$ edition)

Mc. Carthy and Perrlault 2007. Basic Marketing : A Global Marketing Approach (Tata McGraw Hill $15^{\text {th }}$ edition)

Batra, Satish K and Kazmi, S H H 2008. Consumer behavior Text and cases,

Excel

Books

$\left(2^{\text {nd }}\right.$ 